\begin{tabular}{llllll}
\hline Revista Iberoamericana. & Vol. LXV, Núm. 186, Enero-Marzo 1999; 135-148 \\
\hline
\end{tabular}

\title{
POESÍA MEXICANA 1990-1996: \\ GENERACIÓN DE LOS AÑOS CUARENTA
}

\author{
POR \\ Ana Chouciño Fernández \\ Universidad de Santiago de Compostela
}

A tan sólo tres años del próximo milenio, el pulso de la poesía mexicana continúa firme y dando numerosas muestras de innegable fuerza y sana diversidad. El primer síntoma de este buen estado de salud es la última producción de los grandes autores: en 1994 aparece un nuevo título de José Emilio Pacheco (1936), El silencio de la luna y en 1996, la editorial Galería López Quiroga publica Escenarios; Homero Aridjis (1940) lanza en 1991 la segunda edición de su Obra poética. 1960-1990, cuya sección final "Nueva expulsión del paraíso", consta de poemas escritos en 1990; ediciones Heliópolis da a conocer en 1995 el hasta ahora último de los poemarios de Eduardo Lizalde (1929), Otros Tigres, aunque también el año anterior el autor había presentado al público su "indeseable flora parásita" recogida bajo el título Rosas. Jaime Augusto Shelley (1937), uno de los integrantes de "Espiga Amotinada", famoso grupo poético de los sesenta, reúne en Patria Prometida (1996) poemas escritos entre 1984 y 1995. A estos nombres podríamos añadir otros muchos, pero se hace necesario limitar el tema por razones de espacio.

En segundo lugar, la generación de poetas nacidos en los años cincuenta, que aglutina a autores relevantes, se halla cada vez más asentada en el escenario literario mexicano. ${ }^{1}$ Así lo confirman el número y la valía de los títulos que estos autores han dado a conocer recientemente. ${ }^{2}$ Además, la aparición de la colección "Los cincuenta", editada conjuntamente por la Coordinación Nacional de Descentralización y por la Universidad de Ciencias y Artes del Estado de Chiapas, y que presenta tanto poesía como prosa, viene a ratificar la consolidación de este grupo.

La tercera señal de vitalidad de la poesía mexicana es la renovación que implica la aparición de poetas jóvenes, nacidos en la década de los sesenta, que hacen su incursión en el panorama literario por medio de publicaciones en revistas o antologías, como la de José

\footnotetext{
${ }^{1}$ La clasificación de autores por generaciones en este estudio obedece a razones prácticas, pues las diferencias entre ambas no son, a mi modo de ver, demasiado marcadas. A este respecto es necesario recordar lo que ha dicho Vicente Quirarte "La elección por décadas es[...], una fórmula que permite analizar con mayor detalle cada grupo sin embargo, sus afinidades son más frecuentes que sus divergencias" (25).

${ }^{2}$ Los siguientes autores nacidos en la década de los cincuenta han publicado al menos un libro de poemas en los noventa: Vicente Quirarte, Kyra Galván, Myriam Moscona, Verónica Volkov, Coral Bracho, Jorge Esquinca, Francisco Conde, Efraín Bartolomé.
} 
Eduardo Serrato, Diez poetas jóvenes de México. En ella se seleccionan poemas de Julio Hubard, Josué Ramírez, Ana Aridjis o Ernesto Lumbreras, entre otros. Algunos de estos poetas, como en el caso de Hubard y Lumbreras, ya tienen al menos dos libros en el mercado, lo cual augura unos próximos años prometedores para este campo.

Por último, aunque no menos importante, es el definitivo afianzamiento de los poetas nacidos en los cuarenta, a quienes pertenece una parte esencial de la poesía escrita actualmente en México, y que conforman un panorama tan diverso como sobresaliente desde el punto de vista artístico. El presente artículo se centra en las últimas obras de los poetas más significativos de esta generación, con el fin de dar a conocer algunos de los caminos que explora la poesía mexicana de este final de siglo.

En anteriores trabajos he trazado las líneas más llamativas seguidas por la generación objeto de estudio, desde 1970 hasta 1990 (véase Radicalizar e interrogar los límites, y "Poesía del lenguaje en México"). En ellos se hacía alusión a la enorme cantidad de poetas que habían publicado libros a partir del año 1975, aprovechando el buen momento económico que vivía el país y que estimulaba el nacimiento de editoriales, revistas especializadas en poesía, premios y becas. El fenómeno quedaba registrado en la antología de Gabriel Zaid, Asamblea de poetas jóvenes de México, que incluía a más de quinientos poetas. La consecuencia inmediata que todos apuntaron tras la difusión de la antología de Zaid, fue que la cantidad iba en detrimento de la calidad, lo cual no es necesariamente cierto, como afirma Arturo Trejo en el ensayo "Voces de la poesía (1950-1968)":

Muchos críticos se asombran ante la cantidad desorbitante de personas que escriben poemas - que no poetas - pero en realidad eso es relativo: si hay 2 mil escribidores de poemas, en un país con 90 millones de pobladores, la abundancia se relativiza [...] (114).

La situación actual dista bastante de la de hace algunos años: la calidad despunta más que la cantidad. La crisis económica ha puesto a prueba la tenacidad de los escritores y ha servido de una especie de regulador al permitir que sólo algunos, generalmente aquellos que ya tenían cierto nombre y un número apreciable de libros, hayan podido seguir publicando. En la actualidad, la mayor parte de los autores de los cuarenta ya han demostrado su calidad, aún cuando no todos hayan escrito su gran y definitivo libro de poemas.

Por otra parte, se nota la falta de algunas editoriales especializadas en poesía, con gran actividad durante la década de los ochenta, (ediciones Toledo y la colección Cuarto Menguante de la Universidad de Guadalajara). Otras, por fortuna, han hecho posible que se siga conociendo la poesía de los últimos años (las cuidadas ediciones de Aldus y los Cuadernos del Consejo Nacional para la Cultura y las Artes). Además, el que algunos autores de esta generación hayan visto su poesía completa publicada, corrobora que ya no se les puede negar un espacio en el panorama de la literatura mexicana.

Elva Macías, Elsa Cross, Gloria Gervitz, David Huerta y Francisco Hernández son los autores de los cuarenta que merecen ser destacados tanto por la extensión, como por la solidez artística de sus obras. Todos ellos, que sintieron muy de cerca la convulsión originada por los acontecimientos del 68 , comenzaron a publicar en los setenta y desde entonces han continuado obstinadamente su dedicación a la labor poética como una necesidad vital. 
Chiapaneca de origen, Elva Macías nació en Tuxla Gutiérrez en 1944 y ha publicado cuatro libros de poemas desde 1971 a 1989. Viajera por motivos personales, fueron fundamentales para su obra sus estancias en la ex Unión Soviética y China. En sus primeros libros es importante la indagación sobre la propia voz, al tiempo que se dejan sentir las circunstancias de una vida de traslados y viajes. El peso de los patriarcas de su familia, su padre y su abuelo, el poeta popular José Emilio Grajales- y el hecho de que uno de sus bisabuelos fuera uno de los fundadores de su pueblo, Villaflores, explican en cierta manera que los siguientes poemarios tengan como centro los mitos y símbolos de la cultura patriarcal, la cual socava sutilmente (ver los poemarios Imagen y semejanza, de 1982, y Lejos de la memoria, de 1989).

A nivel formal, la poesía de Macías se distingue por un sincretismo y una estética orientalistas que la llevan a escribir poemas generalmente cortos y muy depurados, donde las palabras más que explicar, sugieren. El efecto más obvio de este verso breve es el tono de misterio que crea en torno a la anécdota; el poema se carga de tensión.

Su último título Ciudad contra el cielo (1993) supone un nuevo ahondamiento en la veta orientalista. El libro, con inspiración en Anábasis de Saint-John Perse, (de ahí la relación con lo asiático), poetiza la existencia de una civilización antigua, un pueblo errante, avanzando en caravanas hacia algún lugar. Lo singular de Macías es que, de esa ciudad peregrina, hace surgir la poderosa voz de una mujer, la anciana nodriza del príncipe, que ha sido apartada de él. Desterrada, vaga en torno a la ciudad prohibida, bajo la cual se cobija el príncipe, ya adolescente:

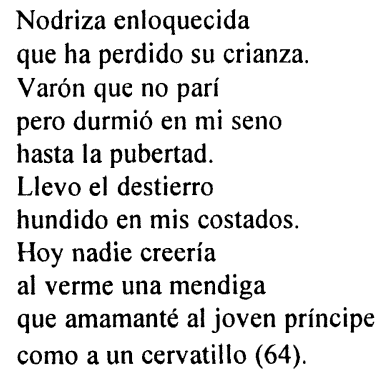

Como Perse, Macías confía con este libro en la renovación de la epopeya, en traer ante la presencia del lector de hoy el clima mítico de antiguas civilizaciones, eso sí, bajo la perspectiva de un personaje femenino que se alza como protagonista de esta emigración.

Las vivencias fuera de su país han influido también en la poesía de Elsa Cross, (Ciudad de México, 1946). Por sus estudios y por sus estancias en la India, su obra deja traslucir la inclinación por la filosofía y el pensamiento hindú (en 1993 apareció una breve plaquette con el título Poemas desde la India que confirman esta sostenida inclinación). Sus poemas son el testimonio de una incesante búsqueda interior y un termómetro de las transformaciones espirituales que ha ido experimentando en varias etapas. La producción poética de esta autora es muy extensa. El volumen Espejo al sol recoge todos los títulos de su poesía desde 
1964 hasta 1981. En la década de los ochenta aparecen Canto malabar (1987), y El diván de Antar, poemario que recibió el Premio Nacional de Poesía Aguascalientes en 1989.

En esta década Cross ha publicado otros cuatro títulos. En el primero de ellos, Jaguar (1991), los poemas componen diversas estampas en las que aparecen alusiones a las antiguas civilizaciones azteca y maya (lugares, mitología), al lado de otras más cercanas (cultos cristianos como el poema "Noche de San Miguel"). El resultado es un libro complejo. El sujeto protagoniza una experiencia en la que el tiempo es el principal parámetro. Junto con algunos poemas bellamente logrados, hay otros cuyos referentes no quedan nada claros. Se habla de la historia, del paso del tiempo, pero se hace en términos que dificultan el esclarecimiento del propósito que encierra el libro. Algunos poemas anuncian que la palabra es origen de todo ("Uxmal"); otros, contraponen el pasado y el presente. En conjunto, el poemario resulta una suerte de reflexiones y evocaciones de la voz poética en torno al tiempo y a la historia, al pasado personal y al pasado mexicano.

Con la excepción de su último poemario Urracas (1995), la obra de Cross tiende al poema extenso, de pensamiento. El tema es con frecuencia la experiencia poética, la indagación en la esencia y en la presencia de la poesía, en el proceso de cómo ésta llega a materializarse. Casuarinas (1992) constituye seguramente el mejor ejemplo de esta búsqueda, y un libro en el que la belleza y la armonía presiden la realización de cada poema. El título responde a la visión que Cross tiene del poeta: la casuarina, árbol originario de Asia, cuyas hojas producen con el viento una especie de sonido musical, es la metáfora que Cross ha elegido para representar a la figura del poeta:

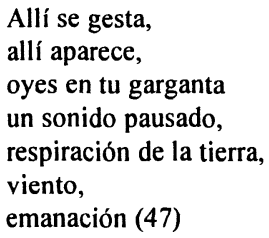

Se trata de una concepción a la vez orgánica y panteísta de la esencia poética. Orgánica en cuanto a que las palabras, semillas del universo, toman posesión del sujeto poético, mero instrumento para originar todas las cosas; y panteísta, en cuanto a que dentro del poema se halla todo, hasta el mismo cuerpo del poeta.

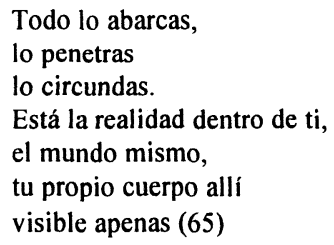

También es llamativa la imagen del poeta como un pararrayos que capta las emanaciones de lo que le rodea. 


\begin{abstract}
Me llamas desde los matorrales, desde las hojas ahítas de tu savia...

[...]Te sigo y pierdo el cuerpo como quien se dispone a naufragar o se vuelve un pararrayos... (7).
\end{abstract}

Por otra parte, el ya mencionado Poemas desde la India, consta de cinco poemas en los cuales escenas y paisajes de aquel país son motivo de reflexión sobre temas similares a los de Casuarinas: "Invicta,/ oigo en mi propio centro/ la frecuencia continua/ ruido del ser [...]" (18). Cross busca el enlace entre el interior del ser y la realidad exterior.

El poemario Urracas, por el contrario, inaugura un tipo distinto de composición dentro de la trayectoria de Cross: por un lado, los poemas se abrevian, y por otro, aparecen ilustrados por los dibujos de tinta de la artista Carmen Parra, siguiendo otra tendencia de la poesía que consiste en aunar poesía con otras artes, ${ }^{3}$ con el fin de conseguir una obra más completa y también más atrayente para el posible lector. Los dibujos representan a las aves mientras los textos hablan de cómo las palabras, representadas por medio de tinta, manchan poco a poco la página en blanco. Además tampoco resulta extraño el título para un libro de poemas, sabiendo que la poesía es un tema frecuente en la obra de Cross, pues la urraca es un ave vocinglera que imita palabras y música.

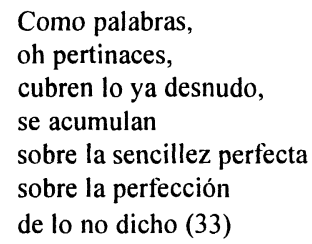

La autorreferencialidad es una de las notas dominantes, como a menudo acontece en este tipo de poemarios con dibujos. Sirvan de ejemplos los siguientes versos: "Suben hasta la superficie letras como burbujas" (35); o "grafías en los muros del túnel" (13).

Otra de las poetas de los cuarenta que deben destacarse es Gloria Gervitz, que nació en la Ciudad de México en 1945 y que ha publicado poesía desde 1979. Si la experiencia de los viajes influye en la producción de Macías y Cross, algo similar sucede con Gervitz, quien acumula esa misma experiencia de forma tanto personal - conoce Nueva York-, como histórica —es nieta de judíos. En esta década Gervitz ha publicado Pythia (1993) y Migraciones (1991), título que forma una nueva versión de sus tres primeros libros, Shajarit (1979), Fragmento de ventana (1986) y Yiksor (1987).

Migraciones nos ofrece la oportunidad de examinar la obra poética de Gervitz de manera global. El título da la primera pista acerca del tema: en su búsqueda en pos de la propia identidad, el sujeto poético trata de recordar a sus antepasados, sobre todo a su abuela,

\footnotetext{
${ }^{3}$ Para un estudio más profundo de la relación entre poesía y otras artes véase Ana Chouciño Fernández, "Alianza entre poesía y otras artes en la poesía última de México", Journal of Interdisciplinary Literary Studies $(8,1996)$, de próxima aparición.
} 
judía que emigró a México desde Kiev. La realidad concreta, el entorno cotidiano de la casa, son el punto de partida para una reflexión sobre sí misma que trasciende el propio marco temporal y lleva a éste a confundirse con el de los familiares ya muertos:

Una gaviota aletea en el cemento

La luz fría en las habitaciones recién pintadas

Huellas de fotos

Mis muertos son tan reales como yo. Les hablo en ruso y en yiddish

Casi me he olvidado del español ¿Qué son las palabras? Sigo confusa, sigo viva. Como antes, cuestiono mis dias. Soy la que era [...] (31)

El conflicto de identidades subrayado por las diferentes lenguas que forman parte de su patrimonio cultural y familiar, es una de las ramas importantes que se desarrollan a partir del tronco de la obra. Este símil adquiere mucho sentido si se observa que en varios de sus poemas Gervitz menciona el sauce. La imagen del árbol ilustra a la perfección la naturaleza de la obra de esta autora. Como ella misma ha dicho: "Tardé años en darme cuenta de que estaba escribiendo desde siempre el mismo poema, como si fuese un árbol al que le crecen nuevas ramas" (Moscona 135).

Otro conflicto viene propiciado por el binomio memoria-olvido, presente en casi todos los poemas y aludido en el título de la tercera parte de Migraciones, "Leteo" (río del olvido en la mitología griega):

A solas despojada de mi nombre

Yiksor Elohim Tú también recuerda a tus muertos[...]

Tu vestido sobre la silla el mismo que ahora se ve en la fotografia

Y la luna la misma de Egipto y Uxmal inamovible y helada

nos sumerge en el olvido[...] (99).

Continuamente la voz poética se formula preguntas que no puede contestar y que sólo la conducen a nuevas consideraciones sobre la propia identidad:

Madre soy yo la buscada

Te he llevado sobre mí

Sintiendo tu peso...

Y yo quería saber

Pero sólo me fue dado preguntar (111-112),

Pythia es otra rama en el tronco de la obra de Gervitz. El libro carece de numeración convencional de páginas, y en su lugar, está divido en cinco secciones. El título se inspira en la sacerdotisa que daba a conocer los oráculos de Apolo. En consecuencia, la facultad de transmitir la palabra tiene aquí un papel esencial: la hablante avanza hacia un mundo oscuro, nocturno, especie de hades, en busca de las palabras. Ya dentro, todo cambia y se ilumina; la luz cobra protagonismo: "Todavía estoy dentro de la luz/pero eres tú la que ha de decirme/ tú la palabra vacía/ la que guarda el nombre" (IV). La hablante se dirige a la luz para que la dote de conocimiento: 


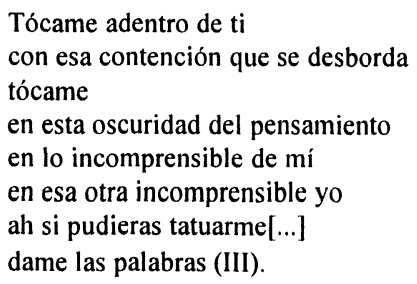

También destacable es la última sección, la quinta, que consta de tres colotipias (fotografias en blanco y negro utilizadas en el siglo XIX), en las que se puede ver a una mujer desnuda, siempre encogida entre ángulos de luzy sombra, remedando el motivo central del libro. Este añadido realza estéticamente el tema y obliga al lector a plantearse las posibilidades que otras artes, en particular las plásticas, ofrecen a la poesía para crear una obra más completa y atractiva.

Si la fotografía forma parte de Pythia, y Urracas incorpora tintas, la misma estrategia de aunar dibujos y poesía es la idea central en Los objetos están más cerca de lo que aparentan de David Huerta (Ciudad de México, 1949), que se publicó en 1991. En muchas de las composiciones de este poemario, los poemas y las tintas se sustentan mutuamente, ya que éstos comentan o hacen referencia a aquéllos. El tema es la escritura, y los poemas y dibujos aluden al proceso de creación, es decir, a cómo nace y se desarrolla el poema.

Huerta inició la década con una obra de temática distinta a la que había frecuentado hasta entonces. Nos referimos a Historia (1990), poemario nada fácil de desentrañar por su heterogeneidad, y que, en clave de plegaria y tono doloroso, habla del amor. La mayoría de los poemas están escritos en versículo, tipo de verso muy trabajado por Huerta. El barroquismo, tan característico de su obra, es una vez más el rasgo a destacar.

No obstante, Huerta no ha querido escribir los convencionales versos de amor. Historia es algo muy diferente por varias razones. Primero, los epígrafes ofrecen una orientación para interpretar los ejes de la obra. El primero de ellos es una cita de Claudio Rodríguez en torno a la naturaleza contradictoria del amor. A continuación, una cita de Luis Fernández apunta a que el autor ve el amor como un tema ya muy gastado, que es necesario reactivar: "Si la palabra es el principio de la acción, liberemos la palabra de la esclavitud doméstica rellenándola de cáncer, del virus más venenoso e incurable, y lancémosla al cuerpo del amor trivial" (9). Segundo, los títulos de los poemas, aunque muy variados, sugieren que bordean lo narrativo. Así, el más largo de ellos, "Historia" se encuentra en el límite entre prosa y verso, y en él se habla de la historia de amor entre un personaje, Simonetta, y el sujeto lírico. Que Huerta está jugando con los conceptos de género es aún más obvio en otro poema, "Seres patológicos", que se subtitula "novela" y que tiene dos protagonistas. Aunque carece de argumento, los conectores sintácticos y los numerosos verbos dan la sensación al lector de que se narra algo:

Con una quietud intolerante, ella se entregaba a las hechicerías del vino.

Pero él sabía cómo 


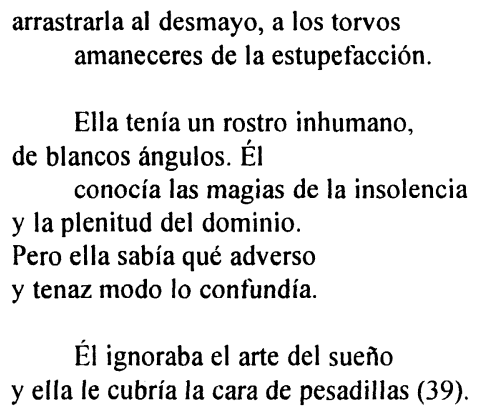

A pesar, pues, de que los poemas de Historia son de muy diversa factura (Huerta nos tenía acostumbrados a libros más orgánicos), vemos que se nutren de la idea del amor impuro y de la destrucción que éste provoca.

Lápices de antes (1993) es el tercer libro que Huerta ha publicado en esta década. Se trata de un breve poemario que consta tan sólo de quince poemas. El título proclama su relación con la escritura (lápices). Luego, los títulos de los poemas hacen pensar en una guía de instrucciones puesto que todos comienzan por la frase "antes de", como si se aludiese a una puesta a punto. En algún poema se aprecia un tono escéptico, a veces incluso burlón, aunque el tema no es particularmente humorístico. Esto es así cuando se combina una acción cotidiana y nada agradable con una reflexión trascendente acerca del ser humano, por ejemplo, en el poema titulado "Antes de echar la basura". En él, el hablante nos invita a detenernos a mirar el mundo antes de tirar la basura, para concluir, en un tono de regocijo, con la certeza de que todos acabaremos en el fondo de los basureros: "para las celebraciones, las mutaciones, la maravilla/ de ser, aún en el fondo de los basurales" (25). Por lo demás, sobresalen las muchas alusiones al lenguaje y a la literatura, siempre haciendo uso del tono sarcástico antes apuntado, que observamos en "Antes de decir cualquiera de las grandes palabras":

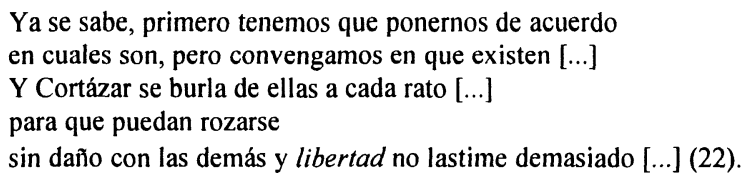

En La sombra de los perros (1996), último de los títulos de David Huerta publicados hasta el momento, también se ha utilizado la fotografía como pauta para una interpretación del libro. Éste se abre con la reproducción fotográfica de un grabado sobre cobre que representa una trenza. Esta pieza de Jim Dine, se transforma en el símil perfecto de la técnica aquí utilizada, pues una serie de palabras clave van apareciendo una y otra vez, en diferentes contextos, recordando al entrelazado de los varios mechones que forman el peinado. En lo temático, la oscuridad, el misterio y el lenguaje, son los hilos que va tejiendo este poemario poblado de imágenes geométricas, elementos minerales y alusiones lingüísticas. Aunque 
aparentemente sencillo por alejarse del largo versículo al que Huerta tiene acostumbrados a sus lectores - Cuaderno de noviembre, Incurable (1976-1987) -, La sombra de los perros es un libro donde, una vez más, el lenguaje es puesto a prueba. El lector percibe la enorme tensión a la que se someten las palabras al ser posicionadas, poema tras poema, en diferentes contextos, tratando de explotar al máximo sus posibilidades significativas.

Francisco Hernández (1946) es, de los poetas nacidos en los cuarenta, el que ha visto su carrera más consolidada en los últimos años. Poeta de muy variadas notas, es tal vez la de los extremos rayantes en la locura la que toca con mayor frecuencia. En esta década, además de una antología personal, El infierno es un decir (1993), y una recopilación de poemas dedicados a la rosa, Hernández ha publicado Poesía reunida (1996), volumen que recoge su obra poética hasta la fecha, desde su primer libro, Gritar es cosa de mudos (1974) hasta los poemas más recientes, agrupados bajo el título Última voluntad. A su producción de años recientes habría que añadir un título aparecido en 1991 en la colección "El ala de tigre" de la UNAM, En las pupilas del que regresa.

Todas las etapas de Hernández merecen la atención del lector, aunque son quizá sus últimos libros, los más narrativos, los que encontramos más interesantes por la relación que establecen con otros personajes de la cultura. Moneda de tres caras, ${ }^{4}$ libro con el que Hernández ganó el premio Xavier Villaurrutia en 1994, contiene estos poemarios: De cómo Robert Schumann fue vencido por los demonios, Habla Scardanelliy Cuaderno de Borneo. El primero, poetiza la locura del músico; el segundo la de Hölderlin (Scardanelli); y el tercero, versa sobre las alucinaciones de otro poeta, Georg Trakl. Todos, por lo tanto, inciden en el tema de los estados mentales límite, como se explicará a continuación.

El largo y sugerente título De cómo Robert Schumann fue vencido por los demonios, presenta una serie de treinta poemas que, inspirados por la música de ese compositor, llegan a componer algunas escenas de su vida, en especial de sus últimos días, momento en el que su demencia se ve agudizada. Se les da voz en los poemas a otros personajes relacionados con Schumann, la niña Clara —quien acabó por casarse con el músico pese a la oposición de su padre-y Wieck, el horrendo progenitor de Clara Schumann.

Los poemas, enunciados en primera, segunda y tercera personas, siguen a un epígrafe de Novalis que alude a la estrecha conexión existente entre poesía y música: "Podría ser que la música y la poesía fueran una misma cosa". Tras el epígrafe, el poema de apertura explica el origen de los treinta que vienen a continuación y que aderezan la historia del personaje:

Miro la música de Schumann como se ve un libro, una moneda o una lámpara.

Ocupa su lugar en la sala situándose, con movimientos felinos, entre el recuerdo de mi padre y el color de la alfombra. De pronto, pájaros muertos estrellan las ventanas.

\footnotetext{
${ }^{4}$ Las tres partes de Moneda de tres caras están incluidas en Poesía reunida, de donde se han extraído todas las citas.
} 
Yo miro la música de Schumann

y escribo este poema

que crece con la noche (371).

Desde el principio, Schumann es una especie de personaje oscuro, maldito, víctima de delirios extremos con los que el sujeto lírico se siente identificado: "Pero tu música, que se desprende/ de los socavones de la demencia/ impulsa por mis venas sus alcoholes benéficos" (372). El resto de los poemas van aclarando esta vinculación hasta el punto de que reconocemos en el yo poético a un ser terriblemente atormentado, cercano también a las fuerzas de lo irracional. El conjunto hace presenciar al lector el lado más oscuro y angustioso de un artista.

Algo semejante se poetiza en Habla Scardanelli. En esta ocasión se proyectan escenas imaginadas por Hernández a propósito de Hölderlin, poeta maldito, recluido por su locura en una torre de Tubinga durante treinta y siete años. El autor ofrece algunos datos de la biografía de este personaje como por ejemplo, su fatal relación amorosa cono Susette Gontard, madre de sus discípulos, o el hecho de que en los últimos años de su vida renunció a su nombre y prefirió llamarse Scardanelli. Hernández describe de la siguiente manera cómo procedió para la ejecución de este libro: "Al escribirlo, he intentado sumergirme en la cabeza de un loco e imaginar sueños, canciones, cantos, monólogos y alucinaciones, no de Hölderlin, sino de ese otro hombre que el autor de Hiperión se creía" (405).

En los poemas que siguen, Scardanelli no es el único protagonista; también se le da voz a la mujer objeto de la pasión del poeta, que él llamaba Diótima o "La griega". El dolor extremo provocado por un estado de perturbación de la mente queda reflejado en cada pieza, en las que el vocabulario parece haber sido cuidadosamente seleccionado para sugerir las condiciones más amargas del sufrimiento humano, las pesadillas más atroces:

Tus muñecas atadas al camastro.

Un martillo golpeándote las sienes.

Ángeles protectores de escorpiones.

Un barco de leprosos por el Neckar.

Erizos a la sombra de tus pechos.

El hacha de los celos en la frente[...] (431).

Cuaderno de Borneo es el último de los libros de Moneda de tres caras. La historia que se recrea es la de otro poeta maldito, Georg Trakl, que vivió entre 1887 y 1914 . Consumidor de estupefacientes y amante incestuoso de su hermana, este poeta vivía obsesionado por la presencia alucinante de demonios.

El libro toma la forma de un diario que recoge las anotaciones de un año de la vida del protagonista. No obstante, se trata de un "pseudodiario" ya que no sigue una rigurosa mención de fechas y sobre todo porque, si el diario está basado en hechos vividos, éste no refleja más que caprichosas invenciones de Hernández, quien revela al final que Trakl jamás estuvo en Borneo. Por tanto, datos biográficos se combinan aquí con la imaginación del autor para dar lugar a un libro en el cual, el atormentado sujeto lírico, se encuentra en una especie de aislamiento de la civilización en la isla de Borneo, desde donde escribe a su 
hermana Sonia. En las alucinaciones del personaje se manifiestan los más extravagantes paisajes, escenas, y seres. Aparecen incluso los personajes femeninos de los otros dos libros de Moneda de tres caras, la niña Clara y Diótima, sirviendo de colofón a este tríptico de artistas.

Las tres figuras de Moneda de tres caras reúnen una serie de características comunes que las convierte en afines para integrar el libro. Todos ellos presentan trastornos de las facultades mentales, por eso el mundo que les rodea resulta patético, absurdo, monstruoso. $\mathrm{Su}$ aguda sensibilidad les lleva a convertirse en individuos rechazados por la sociedad, aislados de ella: Schumann, encerrado en un manicomio, Hölderlin en una torre, y Trakl, aunque ficticiamente, en una isla. Los tres muestran anormalidades en su comportamiento, como intentos de suicidio, cambios de identidad, relaciones incestuosas, abuso de alcohol y drogas. A modo de resumen, es obligado puntualizar que las obras de estos artistas coinciden con la atormentada poesía del propio Hernández, llena a su vez, de demonios y fantasmas (En las pupilas del que regresa consiste en la descripción de una especie de pesadilla cercana al delirio en la que seres extraños y el tema de la muerte tienen una presencia obsesiva).

Los últimos poemas publicados por Francisco Hernández se han agrupado bajo el título Última voluntad. (Textos dispersos). De ellos habría que subrayar, una vez más, el tono violento que caracteriza esta obra desde sus primeros textos. Los temas siguen girando en torno a figuras de la cultura (Matisse, Joseph Brodsky), la crítica incisiva de la naturaleza humana en sus facetas más degradadas, (el poema titulado "Gatarsis" juega con el término "gata" para referirse a mujeres de costumbres poco recomendables), y sobre todo, en torno a la práctica de escribir, tarea sobre la cual impera una visión tremendamente pesimista.

Habiendo comprobado la inclinación de Hernández por la creación de personalidades líricas turbulentas, no sorprende que en los últimos tiempos haya dado vida a Mardonio Sinta, un heterónimo que comparte uno de los rasgos de Schumann, Scardanelli y Trakl, el abuso del alcohol, pero cuya poesía difiere radicalmente de la de los otros personajes. Hernández asume la autoría del prólogo, la biografía y la selección de poemas de Sinta, quien, según cuenta el prologuista, murió en 1990 a consecuencia de una cirrosis hepática. Le gustaba cantar e improvisar coplas al estilo de Martín Fierro, al que recitaba de memoria. Hernández declara haber memorizado algunas de estas coplas y anotado otras para después transcribirlas.

Dos libros de las coplas de Mardonio Sinta han salido a la luz, Coplas a barlovento (1993) y Una roja invasión de hormigas blancas (1994). La voz de Mardonio nada tiene que ver con la de Hernández, ya que la de Sinta es una poesía de sabor popular, que invita al baile, a veces melancólica pero casi siempre divertida, fresca. Mardonio Sinta es "un personaje que es un autor" (89), tal como Arturo Trejo define al heterónimo siguiendo a Octavio Paz, en el ensayo "Los heterónimo de Fernando Pessoa y José Emilio Pacheco". Trejo nos dice además que "es necesario que nos muestre sus obras y que esas obras posean individualidad y carácter propios" (89). Mardonio Sinta cumple, por tanto, las condiciones para ser un heterónimo, lo cual aumenta el abanico de posiblidades poéticas de Francisco Hernández.

El tema central de la poesía de Mardonio, Hernández lo indica, es "el amor con todo su brillo y sus desastres" (10). No obstante, Mardonio habla también de su experiencia con 
la poesía y el canto. Es en estos poemas donde surge la verdadera personalidad artística del improvisador de coplas:

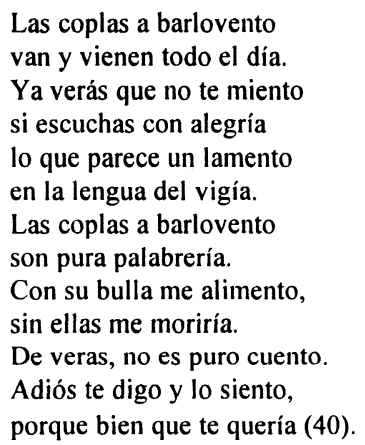

A juzgar por todo lo descrito hasta ahora, la poesía de la generación de los cuarenta representa, tanto en calidad como en cantidad, una aportación más que apreciable al género. Las múltiples propuestas indican una riqueza que es necesario tener en cuenta a la hora de evaluar la lírica de este fin de siglo. En conclusión, puede decirse que, aún cuando cada uno de los poetas modula ya una voz personal, libre de influencias obvias - aunque conociendo bien la tradición-, no resulta difícil describir algunos rasgos comunes significativos.

Primeramente, la de los cuarenta parece ser una de las primeras promociones de poetas en la que la voz femenina no es un hecho aislado ni extraordinario como sucedía en generaciones anteriores. ${ }^{5}$ Las poetas de este grupo como Elva Macías, Elsa Cross o Gloria Gervitz, se han empeñado en su labor desde muy temprano. Siendo sus circunstancias muy dispares, las tres acumulan de una u otra manera experiencias de lo extranjero, ya sea vivido o heredado, y de ello dejan constancia en sus versos: Elva Macías versifica la experiencia del destierro, Elsa Cross incorpora como temas el paisaje y el pensamiento hindú, y Gloria Gervitz plasma en sus poemas su relación con sus antepasados judíos e hispanos. Las tres parecen sospechar que en las tradiciones de las antiguas civilizaciones se encuentra una veta que puede aportar mucho a sus respectivas temáticas. Por ello rescatan la epopeya como género capaz de cantar y contar la historia femenina desde la propia experiencia de la mujer, la cual ha pasado de vivir en el entorno familiar de la casa a conocer, estudiar y viajar por otras culturas tan antiguas como la mexicana.

Otra aportación notable al género viene de la mano de la asociación de poemas con dibujos o fotografias, -Urracas, Pythia, La sombra de los perros, Los objetos están más cerca de lo que aparentan. Además del enriquecimiento estético que esto supone, no hay que olvidar que con esto se pretende una ruptura de líneas entre los géneros, que ahora se

\footnotetext{
5 Después de Rosario Castellanos (1925), pueden citarse a Enriqueta Ochoa (1928), Thelma Nava (1932), o Isabel Fraire (1934). Es, sin embargo, la generación de los cuarenta la que congrega a una cantidad significativa de voces femeninas, lo que se hará aún más notable en la generación siguiente. Es fácil ver esta progresión del número de autoras en la antología de Julian Palley y Aralía López González, De la vigilia fértil (1996).
} 
buscan unos a otros. Algo similar sucede con ciertas obras y poemas que se adentran en los ámbitos de otros géneros literarios como el narrativo, pretendiendo incorporar al poema la capacidad de narrar algo o de inventar personajes, capacidad que la poesía tuvo en la antigüedad pero que luego fue perdiendo por afanes puristas. Vemos que esta línea está siendo especialmente productiva para autores como Hernández.

El conjunto de obras que los poetas de la generación de los cuarenta ha publicado desde 1990, parece apuntar claramente hacia la ruptura de los límites entre poesía y otros géneros o artes. A partir de esto, es de suponer que esta veta continuará intensificándose y diversificándose para dar, si cabe, frutos más logrados. Aunque no se ha examinado aquí la obra de la promoción de los cincuenta, puede afirmarse que los más jóvenes siguen líneas similares a las definidas en este trabajo, y también que fórmulas semejantes seguirán siendo ejercidas en los años próximos. Toda vez que la producción poética mexicana es no sólo abundante, sino también de una calidad literaria de altura, el diagnóstico de su estado no puede ser más positivo.

\section{Obras citadas}

Aridjis, Homero. Obra poética. 1960-1990. México: Joaquín Mortiz 2a edición, 1991.

Chouciño Fernández, Ana. Radicalizar e interrogar los limites: poesía mexicana 19701990. México: UNAM. Colección Biblioteca de Letras, 1997.

"Poesía del lenguaje en México: rechazo de la comunicación convencional". De próxima aparición en la revista Hispanic Review.

Cross, Elsa. Urracas. México: Editorial Aldus, 1995.

Poemas desde la India. México: Universidad Autónoma Metropolitana, 1993.

Casuarinas. México: UNAM, 1992.

Jaguar. México: Ediciones Toledo, 1991.

El diván de Antar. México: Joaquín Mortiz, 1990.

Espejo al sol. Poemas 1964-1981. México: Secretaría de Educación Pública/ Plaza

y Valdés, 1988.

Canto Malabar. México: Fondo de Cultura Económica, 1987.

Gervitz, Gloria. Migraciones. México: Fondo de Cultura Económica, 1991. Pythia. México: Mario del Valle Editor, 1993.

Hernández, Francisco. Poesía reunida (1974-1994). México: UNAM, 1996.

Una roja invasión de hormigas blancas. México: Toque, 1994.

Coplas a Barlovento. México: Universidad Autónoma Metropolitana, 1993.

El infierno es un decir. México: Consejo Nacional para la Cultura y las Artes, 1993. En las pupilas del que regresa. México: UNAM, 1991.

Hubard, Julio. Una turba adorable. México: UAM, 1992.

Presentes Sucesiones. México: Fondo de Cultura Económica, 1988.

Huerta, David. La sombra de los perros. México: Editorial Aldus, 1996.

Lápices de antes. Guadalajara: Toque, 1993.

Historia. México: Ediciones Toledo, 1990.

Los objetos están más cerca de lo que aparentan. México: Galería López Quiroga, 1990. 
Incurable. México: Ediciones Era, 1987.

Cuaderno de Noviembre. México: Ediciones Era, 1976.

Lizalde, Eduardo. Otros tigres. México: Ediciones Heliópolis, 1995. Rosas. México: El Tucán de Virginia, 1994.

Lumbreras, Ernesto. Espuela para demorar el viaje. México: Joaquín Mortiz, 1993 Clamor de agua. México: CNCA, 1990.

Macías, Elva. Ciudad contra el cielo. México: Dirección General de Publicaciones del Consejo Nacional para la Cultura y las Artes, 1993.

Lejos de la memoria. México: Joan Boldó y Climent, 1989. Imagen y semejanza. México: UNAM, 1982.

Moscona, Myriam. De frente y de perfil. Semblanzas de poetas. México: Secretaría General de Desarrollo Social, 1994.

Pacheco, José Emilio. Escenarios. México: Galería López Quiroga, 1996. El silencio de la luna. México: Era, 1994.

Palley, Julian y Aralía López González De la vigilia fértil. Antología de poetas mexicanas contemporáneas. México e Irvine: UNAM/ University of California, 1996.

Quirarte, Vicente. "Reconstrucción en el caos: Territorios de la joven poesía mexicana. Generación 1950-1960". México en el arte 10 (1985): 25-32.

Serrato, José Eduardo. Diez poetas jóvenes de México. México: Alpe Ediciones, 1996.

Shelley, Jaime Augusto. Patria prometida 1984-1995. México: Consejo nacional para la cultura y las artes, 1996.

Trejo Villafuerte, Arturo. La esponja y la lanza. Tuxla Gutiérrez: Consejo Nacional para la Cultura y las Artes; Coordinación Nacional de descentralización. Universidad de Ciencias y Artes del Estado de Chiapas, 1996.

Zaid, Gabriel. Asamblea de poetas jóvenes de México. México: Siglo XXI ediciones, 1980. 